\title{
Impact of Indirect Network Effect between Two Sides on the Diffusion and Pricing of Platform
}

\author{
ZHANG Chuan \\ Dong Ling School of Economics and Management, \\ University of Science and Technology Beijing \\ Beijing, China \\ e-mail:zhangchuanpipi@126.com
}

\author{
HE Weida \\ Dong Ling School of Economics and Management, \\ University of Science and Technology Beijing \\ Beijing, China \\ e-mail: hewd@manage.ustb.edu.cn
}

\begin{abstract}
Platform's diffusion is sophisticated because of indirect network effect between two sides; there will be a peak or several peaks of diffusion rate. Platform's diffusion can be divided to two stages: the stage before its take-off of potential market size and the stage after its take-off of potential market size. At the stage before its take-off of potential market size, platform's diffusion on one side has restriction in its diffusion on the other side. At the stage after its take-off of potential market size, platform's diffusion on one side accelerates its diffusion on the other side.
\end{abstract}

Keywords-Indirect network effect between two sides; Platform; Diffusion; Pricing

\section{INTRODUCTION}

There are two sides or multilateral-sides users in platform product market. As the increasing of one side users, the other side users gain more effect made by consuming platform products. This phenomenon called indirect network effect between two sides which is a vital characteristic of platform products. The market of typical platform products, such as bank card, emporium, e-commerce platform, matrimonial agency, newspaper and operating system, etc. exist two-side users or multilateral sides users. There are indirect network effects between different users.

The characteristics of platform products pricing are different from unilateral market products pricing because of the existing of indirect network effects between two sides. Platform may be to one side charging a low price or providing subsidies on the effect of indirect network effects between two sides. The greater indirect network effects one side contributes, the higher platform pricing subsidies provides. See Rochet, J.-C. et al. (2003, 2006) and Armstrong, M. (2006) for details. In the market entry and starting phase, because of the function of indirect network effects between two sides there is a bilateral cooperative dilemma that is "chicken and egg" which comes first. It needs adopt "divide and conquer" strategy to solve the "chicken and egg" problem. See Caillaud, B. et al. (2003). With the size of the market expansion, the utilities of the users who consume platform products increases. Platform can raise the platform products price, see Sun, M. et al. (2007).

In general, the researches on the function of indirect network effects between two sides mainly focus on the static pricing and static competition of platform bilateral uses. The researches on indirect network effects between two sides impact on the process of static spreading and static pricing of platform products are limited market strategies in the market entry and start phase. There is rare research on the analysis of platform products spreading process and dynamic pricing in indirect network effect between two sides. The paper aims to study the function of indirect network effects between two sides in the process of platform market spreading and explore the influences that the indirect network effects between two sides make to diffusion form and product pricing of platform products and market operation strategy.

\section{PlatForm Products SpREAdING Form}

BASS, F.M. (1969) proposes that products spreading process is similar to the virus propagation process. The nonusers of $t$ time are as the number of users $n(t)=[p+q N(t)][N 1-$ $\mathrm{N}(\mathrm{t})$ ], $\mathrm{N}(\mathrm{t})$ denotes the quantity of users at t time; N1 denotes potential size of the market; $\mathrm{p}$, q denotes external influence coefficient such as the impact of advertising on product diffusion and internal influence coefficient such as the effect of oral communication respectively. BASS diffusion process curve presents smooth S-shaped; Diffusion velocity is bellshaped. There is a diffusion velocity peak point.

There are only one type users in one side product market. One-side product market diffusion is the internal diffusion only among single type users. Different from one side product market diffusion, the platform products diffusion is embodied in the two sides or multilateral sides' market diffusion. For instance, the market of bank card products including the diffusion of ultimate consumer and commercial tenant two types. Platform products in two sides market or multilateral market diffusions influence each other because of indirect network effect between two sides. Platform products' one side diffusion influences other sides potential size of the market, thereby it influences other sides diffusion form. Therefore, the market diffusion influence factors that platform products make to one side including three facets: the exterior factors of unilateral users' diffusion, the interior factors of unilateral users' diffusion and other sides' diffusion scale namely user scale factors.

Multilateral characteristics of platform products make the market diffusion form complicated. In two sides market case which setting the two sides of platform products are A and $\mathrm{B}$. There are unilateral self-diffusion take-off time point $t_{A, S}$ and $t_{B, S}$ which are impacted by unilateral self-diffusion external influence factors and internal influence factors. In 
the meantime, one side market diffusion influences the other side. At a certain time point, one side users scale may dramatically expanding the market size of the other side which called the potential size of the market expansion departure time point. The time points $t_{A, S}$ and $t_{B, S}$ set as $t_{A, O}$ and $t_{B, O}$ respectively. Unilateral self-diffusion take-off time points are determined by p and q, see De Marez Lieven S.B. et al. (2004). Take-off of potential market size time point is determined by the user effect function and user distribution function. For example, assume that the users of side A are coessential. They are all willing to use platform products when the scales of side B users reach to 1000 . Therefore, the time point of side $B$ users' scale reaching to 1000 is the time point $t_{\mathrm{A}, \mathrm{O}}$ of side A potential market scale expansion take-off.

Unilateral self-diffusion take-off time point of platform product market makes one time rapidly expanding of product market. The take-off of potential market size time point makes rapidly expanding once again because of the potential market size rapid expansion. However, the rapid expansion of one side market may influence the market diffusion velocity of the other side at the same time. It may also bring about a new rapid diffusion of the other side market. The indirect network effects of platform product market between two sides make the market diffusion form of platform market complicated. It mainly shows in the diffusion form of a certain side. Precisely, diffusion process curve is probably Sshaped or not. It may also probably be bell-shaped or not. Followings are analysis about this issue:

(i) If the points $t_{A, S}, t_{B, S}, t_{A, O}$ and $t_{B, O}$ have large differences, there are four diffusion velocity peak points in the diffusion form. The diffusion velocity is neither bellshaped nor $\mathrm{S}$ shaped. As shown in Fig.1;

(ii) If the points $t_{A, S}, t_{B, S}, t_{A, O}$ and $t_{B, O}$ are pretty close, there is a certain middle time point's diffusion velocity reaching to maximum value in the diffusion form. The diffusion velocity curve and diffusion process curve are the same as unilateral market products' diffusion velocity curve and diffusion process curve. As shown in Fig. 2;

(iii) If the points $t_{\mathrm{A}, \mathrm{S}}, \mathrm{t}_{\mathrm{B}, \mathrm{S}}, \mathrm{t}_{\mathrm{A}, \mathrm{O}}$ and $\mathrm{t}_{\mathrm{B}, \mathrm{O}}$ exist two time points that one is closer to each other, the other is large different from others, diffusion form shows that there are multiple diffusion velocity peak points. The number of the peak points is between $t_{A, S}$ and $t_{B, O}$. The diffusion process curve is not bell-shaped. The diffusion is not S-shaped.

(iv) Because the time points of the two sides are different, the diffusion form of platform products in two different sides market may be different.
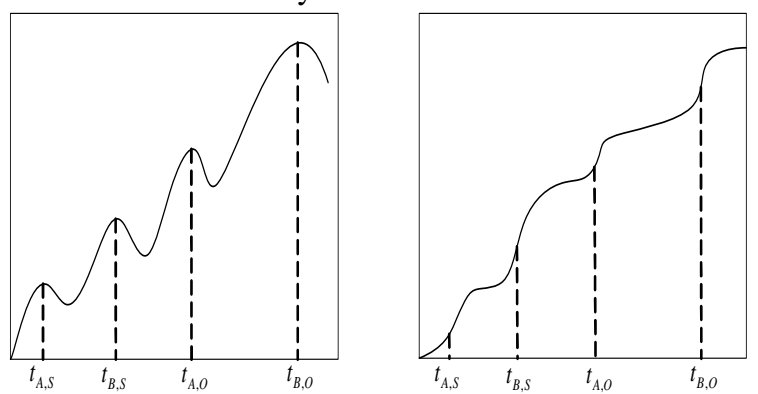

(a) Diffusion velocity curve (b) Diffusion process curve

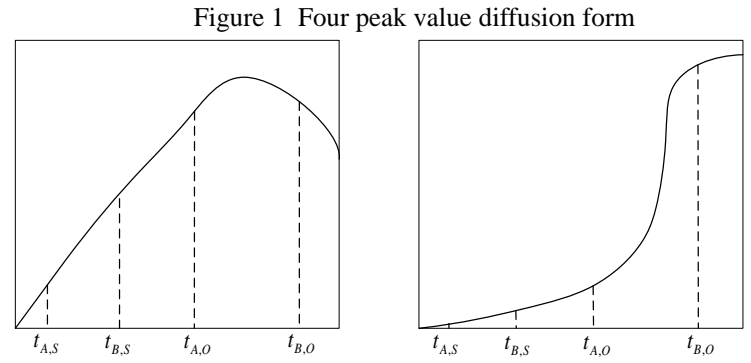

(a) Diffusion velocity curve (b) Diffusion process curve Figure 2 Single-peaked value diffusion form

The analysis results of above-mentioned platform products platform products are consistent. Multi-modal diffusion form of platform products is common. China mobile WAP business development experience in 2000, 2003-2006 and 2009 developed rapidly. The business of 2001-2002 and 2007-2008 sank into a low valley. Web portals developed rapidly after 1999-2002 and 2004. A large number of web portal suffered financial crisis and went bankrupted in 2003 and 2004. The diffusion curve of considerable ICT products, such as WAP business, PC market, XML, 3-D WEB and Web Portal, etc. are doublet shaped (Saddle-shaped) or multi-modal shaped. More and more ICT products demonstrate platform products characteristics because of standardization advancing or other reasons. The diffusion velocity curve of "Doublet shaped" or "Saddle-shaped" is common in ICT products, see De Marez Lieven S.B. et al. (2004).

\section{The Phased Pricing Of Platform Products DIFFUSION}

The diffusion scale of one side user market influences the potential market scale of the other users. According to whether it is reaching the take-off point of the potential market size expansion, platform products in certain diffusion can be divided into two stages: the stage before its take-off of potential market size and the stage after its takeoff of potential market size.

At the stage before its take-off of potential market size, platform products market diffusion is unilateral diffusion of the two sides respectively. Because the users' scale of the other side is small, the users of one side derive lower utility from using platform product. The scale of potential users market is very small. The function of indirect network effect between two sides manifests that the scale of one side restricts market diffusion of the other side. At the stage after its take-off of potential market size, indirect network effect between two sides plays a dominant role which makes the potential market scale rapidly expand and gain positive feedback from diffusion of the two sides. Because of the users scale of the other side increasing, the users of one side derive high utility from using platform products. The scale of potential users market is large. The function of indirect network effect manifests mutual promoting as the scale of the two sides users increases.

The mode of action of indirect network effect is different in the two diffusion stages. At the stage before its take-off 
of potential market size, the function of indirect network effect manifests mutual restriction between two sides diffusion. At the stage after its take-off of potential market size, the function of indirect network effect manifests mutual promotion between two sides diffusion. The functions are always expressed as two different extreme cases which are the extreme pessimistic expectation and the extreme optimism expectation in some involved network effect expression; see Hagiu, A. (2006). In extreme pessimistic cases, no users use the platform products. Indirect network effect between two sides actually restricts the diffusion of platform products. In extreme optimism cases, all the users use platform products. Indirect network effect between two sides promotes the diffusion of platform products.

The different functions of indirect network effect between two sides in different diffusion stages determine that pricing strategy of platform products should be different in different stages. At the stage before its take-off of potential market size, there is a bilateral cooperative dilemma that "chicken and egg" who comes first because of the restriction function of indirect network effect between two sides. In order to make the clients accept that solving the "chicken and egg" problem it providing lower cost services for one side users of platform or even paying for it. After accumulating a certain amount of users through providing lower cost service and even paying for services, and then charge higher price for profits from the other side we call it "divide and conquer" strategy, see Caillaud, B. et al. (2003). For instance, Microsoft invested in application software developers. Palm helped outside developers establish and external businesses. Diners Club, American Express and Bank of America Corporation chose to charge lower expenses at the initial diffusion stage.

The platform whose purpose is to maximize profits cannot accept charge lower expenses or free services forever. At the stage after its take-off of potential market size, the function of indirect network effect manifests mutual promotion between two sides diffusion. With the users' effects getting more and more through using platform products, the platform can increase products and service price. The research of Sun and TSE (2007) manifests that after reaching a certain business scale, the benefits made by indirect network effect between two sides increases and the two sides users can withstand higher prices. The optimal dynamic pricing strategy of platform is to improve business expenses gradually. Diners Club's pricing strategy is successful. At the business development initial period, platform provides free services for individual users. Diner Club found that its business took off rapidly soon, and then Diner Club adopted charging individual users 3 dollars annual fee strategy. One year later the platform charged individual users 18 dollars annual fee. In 1958, the platform charged individual users 26 dollars annual fee.

However, before the platform product market diffusion entering into the stage after its take-off of potential market size, it may be made the platform products diffusion incomplete in two sides market even failed if it changes "divide and conquer" market strategy. At the stage before its take-off of potential market size, users market may decrease dramatically by adjusting users' subsidy and lower expense services. The decreasing of potential user market makes the market diffusion of platform products could not advance to the mutual promotion stages of indirect network effect between two sides. Therefore, the market diffusion between two sides may end in failure. In May 2002, 263 lost its market dominant position because of adopting charging individual users email service fee strategy. IBM attempted to expanse into PC operating system field and developed itself operation system OS/2. This made IBM lost its PC market share thorough. The key reason of slow development of China mobile 2007-2008 WAP business is China Mobile adjusted the business distribution mode among WAP portals. The failed cases in the diffusion processes of these platform products manifest that selecting the right time to adjust pricing strategy of platform products is very important. Maintaining the Integrity of the Specifications

\section{CONCLUSION}

This paper finds that platform's diffusion is sophiscated because of indirect network effect between two sides, there will be a peak or several peaks of diffusion rate. Platform's diffusion can be divided to two stages: the stage before its take-off of potential market size and the stage after its takeoff of potential market size on the base of whether reaching the take-off point of potential market size. At the stage before its take-off of potential market size, platform's diffusion on one side has restriction in its diffusion on the other side. It needs to conquer the "chicken and egg" dilemma through proper pricing strategy. At the stage after its take-off of potential market size, platform's diffusion on one side accelerates its diffusion on the other side. And then it can appropriately adjust "divide and conquer" pricing strategy and raise pricing level. Adjusting pricing strategy may lead to market diffusion of platform products failure at the stage before its take-off of potential market size. The conclusion reminds that the platform products operators should be prudent in adjusting pricing and should not adjust platform products' price of the two sides at will.

\section{REFERENCES}

[1] Armstrong, M. "Competition in Two-Sided Markets." RAND Journal of Economics, Vol.37 (2006): pp. 668-691.

[2] BASS, F.M. "A new product growth for model consumer durables." Management Science, Vol.15(1969): pp. 215-227.

[3] Caillaud, B., Jullien, B. "Chicken \& Egg: Competition among Intermediation Service Providers." RAND Journal of Economics, Vol. 34(2003): pp. 309-328.

[4] De Marez Lieven S.B., Verleye Gino B.M. "ICT-innovations today: making traditional diffusion patterns obsolete, and preliminary insight of increased importance." Telematics and Informatics, Vol. 21(2004): pp. 235-260..

[5] Hagiu, A. "Pricing and commitment in two-sided markets." RAND Journal of Economics, Vol. 37(2006): pp. 720-737.

[6] Rochet, J.-C., Tirole, J. "Platform competition in two-sided markets." Journal of the European Economic Association, Vol. 1 (2003): pp. 990-1029

[7] Rochet, J.-C., Tirole, J. "Two-Sided Markets: A Progress Report." RAND Journal of Economics, Vol.37 (2006): pp. 645-667. 
[8] Sun, M., TSE, E. "Sustainable growth of payment card networks: a two-sided market approach." Journal of Business Strategies, Vol. 24(2007): pp. 165-191.
[9] Sun, M., TSE, E. "When does the winner take all in two-sided markets?" Review of Network Economics, Vol.6 (2007): pp. 16-40.

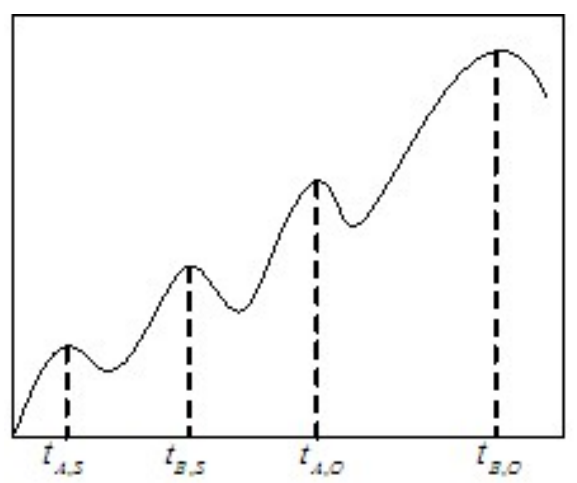

(a) Diffusionvelocity curve

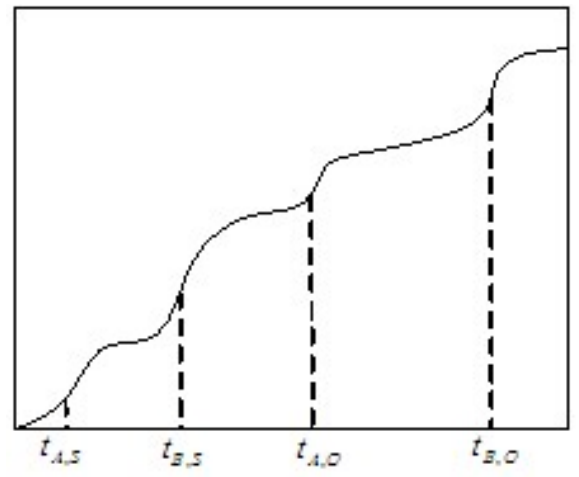

(b) Diffusion process curve.

Figure 3 Four peak value diffusion form

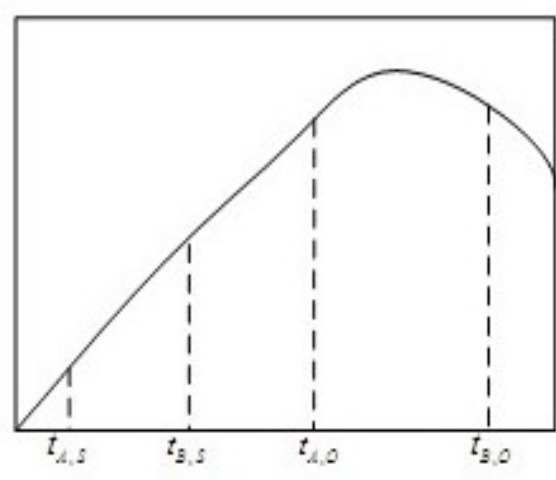

(a) Diffusion velocity curve

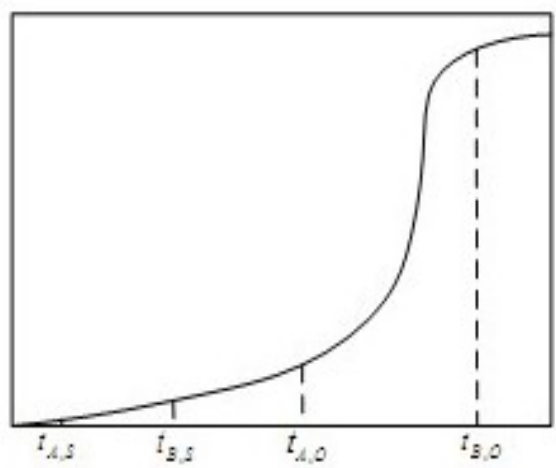

(b) Diffusion process curve.

Figure 4 Single-peaked value diffusion form 